\title{
Patterns of Care in Pediatric Craniopharyngioma: Outcomes Following Definitive Radiotherapy
}

\author{
TANNER K. HILL ${ }^{1}$, MICHAEL J. BAINE ${ }^{1}$, VIVEK VERMA ${ }^{2}$, MORSHED ALAM ${ }^{3}$, \\ ELIZABETH R. LYDEN ${ }^{3}$, CHI LIN ${ }^{1}$, EILEEN P. CONNOLLY ${ }^{4}$ and CHI ZHANG ${ }^{1}$ \\ ${ }^{I}$ Department of Radiation Oncology, University of Nebraska Medical Center, Omaha, NE, U.S.A.; \\ ${ }^{2}$ Department of Radiation Oncology, Allegheny General Hospital, Pittsburgh, PA, U.S.A.; \\ ${ }^{3}$ Department of Biostatistics, College of Public Health, University of Nebraska, Omaha, NE, U.S.A.; \\ ${ }^{4}$ Department of Radiation Oncology, Columbia University Medical Center, New York, NY, U.S.A.
}

\begin{abstract}
Background/Aim: Few data are available on the utility of definitive radiation therapy $(R T)$ for pediatric craniopharyngioma. This study sought to evaluate practice patterns and patient outcomes using the Surveillance Epidemiology and End Results database from 2004-2014. Materials and Methods: Overall survival (OS) was compared between five treatment groups, definitive radiation therapy $(R T)$, gross total resection (GTR), subtotal resection (STR), $S T R+R T$, and observation/biopsy only, using Kaplan-Meier analysis and log-rank tests. Multivariate Cox proportional hazards modeling determined variables independently associated with OS. Results: A total of 373 patients met the study criteria. GTR and definitive RT conferred superior OS than observation/biopsy ( $p=0.008$ and 0.029), but were equivalent to $S T R+R T(p=0.350$ and 0.200). GTR was associated with a higher OS than STR $(p=0.027)$. On multivariate analysis, $S T R+R T, G T R$, and definitive $R T$ were associated with statistically equivalent OS $(p=0.990)$. Conclusion: Definitive RT for pediatric craniopharyngioma affords similar outcomes to established modalities of therapy such as GTR and STR+RT.
\end{abstract}

Originating from remnants of Rathke's pouch, craniopharyngiomas are rare tumors that have both solid and cystic components; this neoplasm comprises $5-10 \%$ of pediatric brain tumors (1-3). There are two main approaches to treatment, including surgery in efforts to achieve GTR, versus a more conservative STR followed by adjuvant RT to combat residual

Correspondence to: Chi Zhang, MD, Ph.D., Department of Radiation Oncology, University of Nebraska Medical Center, Buffett Cancer Center, 505 S 45th St, Omaha, NE 68106, U.S.A. Tel: +1 4025523147, Fax: +1 4025527799, e-mail: chi.zhang@unmc.edu

Key Words: Craniopharyngioma, radiotherapy, surgery, survival, pediatrics. disease. Although aggressive surgical approaches may more likely achieve GTR, there may be substantial iatrogenic morbidity and mortality, including effects on the visual, endocrine, and neurocognitive systems $(4,5)$.

To this extent, administration of definitive RT may prevent some surgery-related complications, but this is a nonstandard therapy on account of few available data. Smallvolume retrospective studies (6-9) and a population-based analysis (10) have shown comparable outcomes between definitive RT, STR+RT, and GTR. Corresponding data in pediatric patients are much scarcer (11-13), likely because surgery-based therapy remains much more studied and there is reluctance to irradiate children. Nevertheless, lack of surgery does indeed occur for various reasons (e.g. refusal by patients and/or parents), and large studies of definitive RT (without attempted surgery) in the pediatric population are currently lacking.

Hence, this question was evaluated using the Surveillance, Epidemiology, and End Results (SEER) population-based dataset. Specifically, the practice patterns and outcomes between STR+RT, GTR, and definitive RT were evaluated.

\section{Materials and Methods}

Using the SEER database. ICD-O-3 codes for craniopharyngioma (9350-9352) were used to identify all craniopharyngioma cases from 2004 to 2014, after the SEER program started to collect nonmalignant CNS tumors. Age adjustment was based on the 2000 US standard population. The surgical technique was categorized into four groups: no surgical intervention (observation), biopsy only, STR, and GTR, as referenced in previous publications $(10,14)$. For brain sites $(\mathrm{C} 71.0-$ C71.9, C72.0-C72.9), observation/biopsy referred to surgical codes of 00 and 20. STR was defined as codes 21, 40, and 90. GTR included codes 30 and 55. For other sites (C75.1, C75.2 and C75.3), the observation/biopsy group referred to code 00 and 27 . The STR group was defined as codes 30 and 50 . The GTR group included codes 40 and 60. The definitive RT (observation/biopsy+RT) group was defined as patients receiving only RT (observation+RT) or biopsy followed by RT (biopsy+RT). 
Following calculation of age-adjusted disease incidences, age was divided into three groups: 0-5, 6-12, and 13-20. The age ranges were chosen based on disease incidence and in order to maintain uniformity between groups when the sample size is very low.

Statistics were performed with SAS software (Cary, NC); $p<0.05$ was considered statistically significant. Estimates of overall survival (OS) were determined based on the Kaplan-Meier method; survival time referred to the interval between the date of diagnosis until death or censored at date of last follow-up. Although the SEER database categorizes cause-specific survival, the comparison of this parameter between groups was not indicated in a low sample size pediatric population with few cause-specific events. The log-rank test was used to compare survival between patient groups. Cox proportional hazards regression modeling was used for multivariate analysis.

\section{Results}

A total of 373 cases were identified from the SEER database. Of these, 97 (26\%) were aged 0-5, 150 (40\%) aged 6-12, and $126(34 \%)$ aged 13-20. Table I displays selected clinical characteristics of the patient population. Most patients were Caucasian. Patients were relatively similar in terms of gender and, of the cases with available size, most had tumors $<3 \mathrm{~cm}$.

Table II shows patterns of care by age group based on five primary categories: definitive RT, GTR, observation/biopsy only, STR, and STR+RT. The most common treatment methods overall were STR (27\%), observation/biopsy only (25\%), and GTR (25\%). Definitive RT was administered in $7 \%$ of patients $0-5$ years old, $9 \%$ in those aged $6-12$, and $14 \%$ in the $13-20$ cohort.

Median follow-up was 49 months (range=0-119 months). Figure 1 illustrates OS between the five treatment categories, with a statistically significant difference $(p=0.020)$. When performing a direct comparison between subsets, there were significant differences in OS between GTR and STR $(p=0.027)$, GTR and observation/biopsy only $(p=0.008)$, and definitive RT and observation/biopsy only $(p=0.029)$. Figure 2 shows no statistical differences between definitive RT, GTR, and STR+RT ( $p=0.330)$.

Cox multivariate analysis for overall survival revealed that treatment (definitive RT vs. others), tumor size, sex, and age did not show statistically significant correlation with OS. However, hazard for definitive RT is reported as zero, which might not have a meaningful interpretation as no death is recorded for definitive RT category.

\section{Discussion}

Population-based analyses are excellent ways to study rare instances of an uncommon neoplasm. The National Cancer Institute's SEER program includes approximately $28 \%$ of the population of the United States, and the updated SEER database allowed for evaluation of the largest cohort of pediatric craniopharyngioma patients ever available for the
Table I. Demographic and clinicopathologic characteristics of the patient population.

\begin{tabular}{lc}
\hline & $\mathrm{N}(\%)$ \\
\hline Total & $\mathrm{N}=483(100.0)$ \\
Gender & \\
Male & $246(50.9)$ \\
Female & $237(49.1)$ \\
Age $(\mathrm{y})$ & \\
$0-5$ & $127(26.3)$ \\
$6-12$ & $194(40.2)$ \\
$13-30$ & $162(33.5)$ \\
Race & \\
White & $359(74.3)$ \\
Black & $66(13.7)$ \\
Other/unspecified & $58(12.0)$ \\
Histology & \\
Adamantinomatous & $169(35.0)$ \\
Median age (range) (y) & $9(0-20)$ \\
Mean tumor size (range) (mm) & $37(1-330)$ \\
Papillary & $6(1.2)$ \\
Median age (range) (y) & $17(3-19)$ \\
Mean tumor size (range) (mm) & $38(28-40)$ \\
Unknown & $308(63.8)$ \\
Size of tumor (cm) & \\
$<3$ & 127 \\
3-5 & 160 \\
$\geq 5$ & 82 \\
Unknown & 114 \\
\hline
\end{tabular}

Table II. Treatment stratified by age group .

\begin{tabular}{lccc}
\hline & \multicolumn{3}{c}{ N (\%) } \\
\cline { 2 - 4 } Treatment & Age 0-5 & Age 6-12 & Age 13-20 \\
\hline Observation/Biopsy & $29(29.9)$ & $35(23.3)$ & $29(23.0)$ \\
GTR & $23(23.7)$ & $44(29.3)$ & $25(19.8)$ \\
STR only & $31(32.0)$ & $34(22.7)$ & $35(27.8)$ \\
STR+RT & $7(7.2)$ & $23(15.3)$ & $19(15.1)$ \\
Definitive RT & $7(7.2)$ & $17(9.3)$ & $18(14.3)$ \\
Total & 97 & 150 & 126 \\
\hline
\end{tabular}

assessment of pattern of care and treatment outcomes. We showed that the most common treatment paradigms are nonRT-based: STR, observation/biopsy only, and GTR. We also illustrated for the first time that in this population, definitive RT was associated with excellent outcomes that are not inferior to established treatment paradigms.

Definitive radiation therapy in pediatric craniopharyngioma is very rare and has only been reported in a few small retrospective studies (11-13). A comprehensive review of several small-volume $(\mathrm{n} \leq 10)$ series are presented by Kiehna 


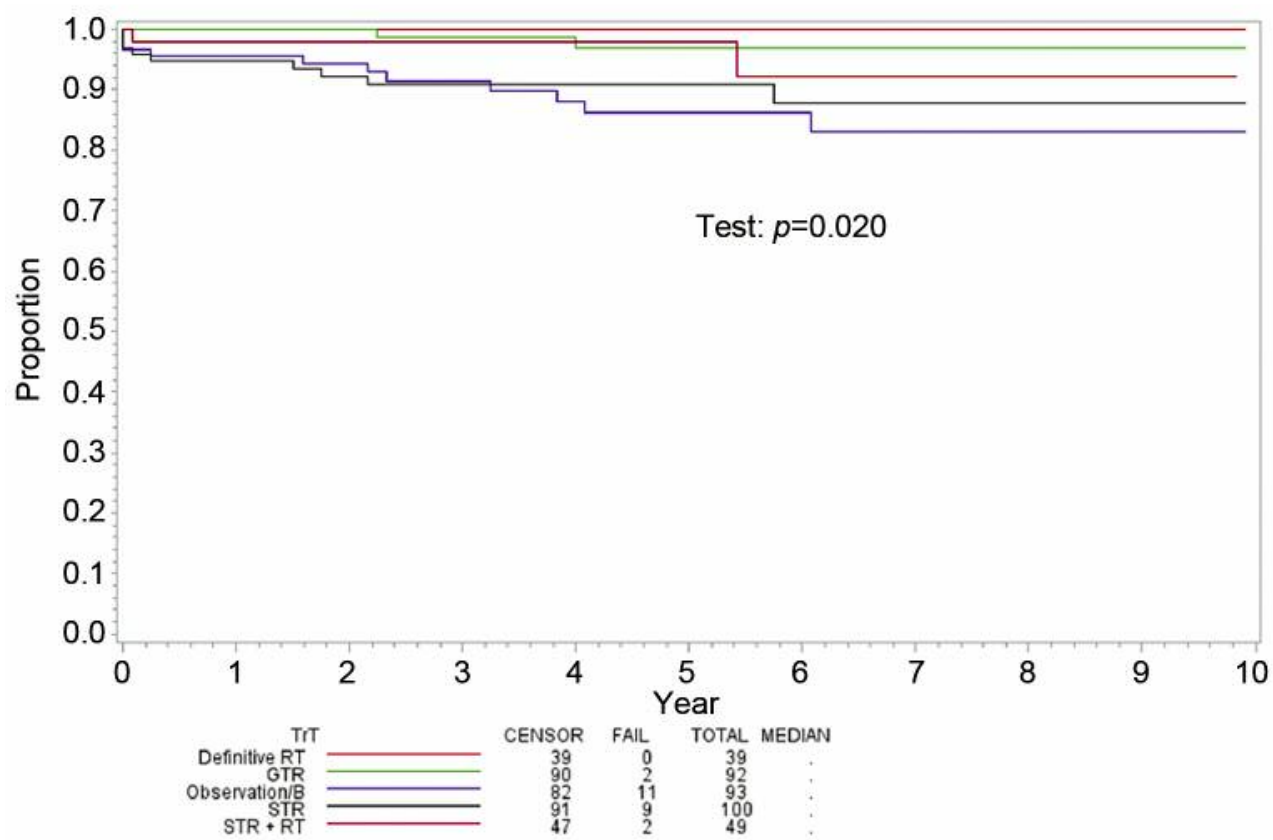

Figure 1. Overall survival among patients undergoing definitive $R T, G T R, S T R, S T R+R T$, and observation/biopsy. RT: Radiotherapy; GTR: gross total resection; STR: subtotal resection.

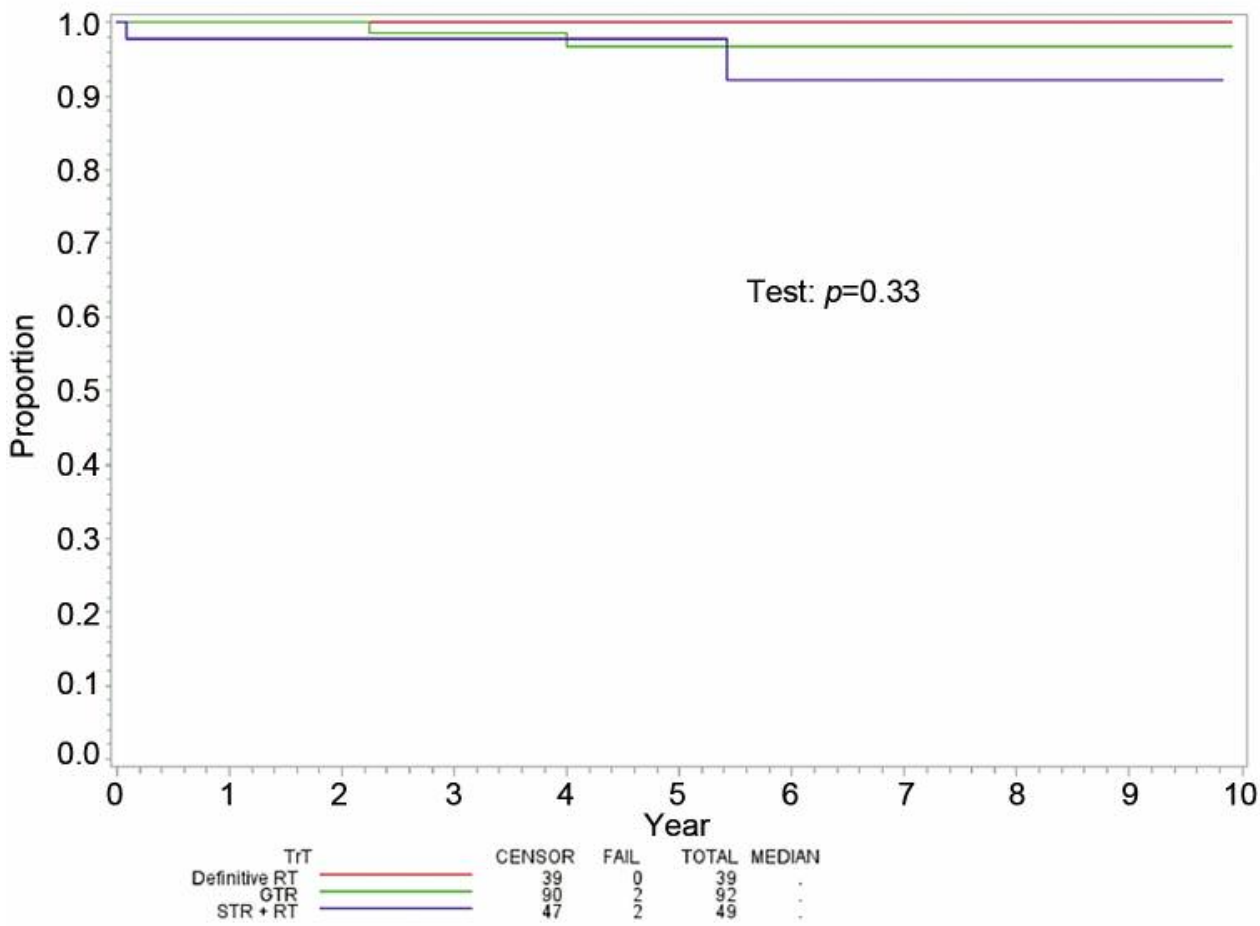

Figure 2. Overall survival among patients undergoing definitive RT, GTR, and STR+RT. RT: Radiotherapy; GTR: gross total resection; STR: subtotal resection.

and Merchant, displaying numerically similar outcomes as either GTR or STR+RT patients, although most patients therein were treated 3-4 decades ago (11). A series of studies from Children's Hospital in Boston reported treatment of nine children (age $\leq 21$ ) with no recurrences at time of last followup (12-13). 
It is acknowledged that for a benign tumor, observing significantly improved survival with a given intervention is relatively uncommon. Although the SEER database does not record other relevant endpoints such as local control or toxicities, this information is necessary to make a valid conclusion of definitive RT in the pediatric population. However, the display of equivalent survival between definitive RT and STR+RT and GTR signals some degree of equivalence, since the definitive RT population could have been "higher-risk" if surgery could not be performed owing to various reasons (e.g. prior morbidity or serious concurrent medical illness). While there were too few events to glean statistical significance from these data, it is implied that definitive RT does not produce inferior outcomes to surgicalbased approaches.

From these data, it is clear that, numerically, the utilization of definitive RT increases with age group, after which figures may appear similar to its utilization in adult patients (10). However, there is reason to believe that definitive RT could increase in the future, thus making the results of this investigation important to consider. The emerging utility of proton RT (PRT) has been especially pronounced in children, for which delivery of a lower integral dose may lead to fewer secondary neoplasms and treatment-related adverse events (15); PRT is also quite cost-effective in these neoplasms, as a result $(16,17)$. For pediatric craniopharyngioma, delivery of PRT affords similar natural history during and after therapy, with acceptable toxicities (18). What remains to be more completely addressed are cognitive outcomes following PRT for these patients (19-20).

There are several caveats to this work. Retrospective selection biases are present in any study, including a lack of precise reasons for delivering any type of therapy (or lack thereof). Though progression-free survival is typically used to compare different modalities at risk for local recurrence, it is not available from the SEER database. Additionally, quantification of treatment-related morbidities is also not given in the SEER dataset, which is necessary to evaluate the true utility of definitive RT in this population. The observation/biopsy group was found to have relatively high survival, which may have been due to missing documentation of delayed RT data, or good salvage options.

In summary, this population-based analysis, the largest of this population to date, did not observe any survival differences in craniopharyngiomas treated with definitive RT and surgical-based approaches. This has implications on patient counseling if surgery is not an option for patients and/or parents, for various reasons. It is unlikely that prospective trials will be conducted on this circumstance owing to the rarity of these neoplasms in this patient population. Therefore, these hypothesis-generating data must be corroborated by multi-institutional experiences.

\section{Conflicts of Interest}

The Authors declare no conflicts of interest regarding this study.

\section{Authors' Contributions}

TH was responsible for data extraction, initiating data analysis, manuscript writing, and manuscript revisions; MB was responsible for partial data analysis, manuscript writing, manuscript revisions, and aided in project conceptualization; VV helped with overseeing data analysis and aided in both conceptualization and manuscript revisions; MA was responsible for data analysis and manuscript revisions with regards to biostatistics; EL was responsible for overseeing data analysis and for helping with manuscript revisions; CL helped with project conceptualization, conceptualization of data analysis, and manuscript revisions; EC helped with project conceptualization; and $\mathrm{CZ}$ was primarily responsible for project conceptualization and coordinating efforts in data analysis, manuscript writing, and revisions.

\section{References}

1 Petito CK, DeGirolami U and Earle KM: Craniopharyngiomas: a clinical and pathological review. Cancer 37(4): 1944-1952, 1976. PMID: 1260697

2 Russell DS and Rubinstein LJ: Pathology of tumours of the nervous system. 5th ed. Baltimore, Williams \& Wilkins, 1989.

3 Bunin GR, Surawicz TS, Witman PA, Preston-Martin S, Davis $F$ and Bruner JM: The descriptive epidemiology of craniopharyngioma. J Neurosurg 89(4): 547-551, 1998. PMID: 9761047, DOI: 10.3171/jns.1998.89.4.0547

4 Sughrue ME, Yang I, Kane AJ, Fang S, Clark AJ, Aranda D, Barani IJ and Parsa AT: Endocrinologic, neurologic, and visual morbidity after treatment for craniopharyngioma. J Neurooncol 101(3): 463-476, 2011. PMID: 20535527

5 Yasargil MG, Curcic M, Kis M, Siegenthaler G, Teddy PJ and Roth P: Total removal of craniopharyngiomas. Approaches and long-term results in 144 patients. J Neurosurg 73(1): 3-11, 1990. PMID: 2352020

6 Merchant TE, Kiehna EN, Sanford RA, Mulhern RK, Thompson SJ, Wilson MW, Lustig RH and Kun LE: Craniopharyngioma: the St. Jude Children's Research Hospital experience 1984-2001. Int J Radiat Oncol Biol Phys 53(3): 533-542, 2002. PMID: 12062594

7 Karavitaki N, Brufani C, Warner JT, Adams CB, Richards P, Ansorge O, Shine B, Turner HE, and Wass JA: Craniopharyngiomas in children and adults: systematic analysis of 121 cases with long-term follow-up. Clin Endocrinol (Oxf) 62(4): 397-409, 2005. PMID: 15807869

8 Stripp DC, Maity A, Janss AJ, Belasco JB, Tochner ZA, Goldwein JW, Moshang T, Rorke LB, Phillips PC, Sutton LN and Shu HK: Surgery with or without radiation therapy in the management of craniopharyngiomas in children and young adults. Int J Radiat Oncol Biol Phys 58(3): 714-720, 2004. PMID: 14967425

9 Lin LL, El Naqa I, Leonard JR, Park TS, Hollander AS, Michalski JM and Mansur DB: Long-term outcome in children treated for craniopharyngioma with and without radiotherapy. J Neurosurg Pediatr 1(2): 126-130, 2008. PMID: 18352781 
10 Zhang C, Verma V, Lyden ER, Horowitz DP, Zacharia BE, Lin $\mathrm{C}$ and Connolly EP: The role of definitive radiotherapy in craniopharyngioma: a SEER analysis. Am J Clin Oncol 41(8): 807-812, 2017. PMID: 28263230, DOI: 10.1097/ COC.0000000000000378.

11 Kiehna EN, and Merchant TE: Radiation therapy for pediatric craniopharyngioma. Neurosurg Focus 28(4): E10, 2010. PMID: 20367354

12 Hetelekidis S, Barnes PD, Tao ML, Fischer EG, Schneider L, Scott RM and Tarbell NJ: 20-year experience in childhood craniopharyngioma. Int J Radiat Oncol Biol Phys 27(2): 189195, 1993. PMID: 8407391

13 Scott RM, Hetelekidis S, Barnes PD, Goumnerova L and Tarbell NJ: Surgery, radiation, and combination therapy in the treatment of childhood craniopharyngioma--a 20-year experience. Pediatr Neurosurg 21: 75-81, 1994. PMID: 7841082

14 Zacharia BE, Bruce SS, Goldstein H, Malone HR, Neugut AI and Bruce JN: Incidence, treatment and survival of patients with craniopharyngioma in the surveillance, epidemiology and end results program. Neuro Oncol 14(8): 1070-1078, 2012. PMID: 22735773

15 Merchant TE, Hua CH, Shukla H, Ying X, Nill S and Oelfke U: Proton versus photon radiotherapy for common pediatric brain tumors: comparison of models of dose characteristics and their relationship to cognitive function. Pediatr Blood Cancer 51(1): 110-117, 2008. PMID: 18306274

16 Verma V, Mishra MV and Mehta MP: A systematic review of the cost and cost-effectiveness studies of proton radiotherapy. Cancer 122(10): 1483-1501, 2016.
17 Verma V, Shah C, Rwigema JC, Solberg T, Zhu X and Simone CB 2nd: Cost-comparativeness of proton versus photon therapy. Chin Clin Oncol 5(4): 56, 2016. PMID: 27506804

18 Bishop AJ, Greenfield B, Mahajan A, Paulino AC, Okcu MF, Allen PK, Chintagumpala M, Kahalley LS, McAleer MF, McGovern SL, Whitehead WE and Grosshans DR: Proton beam therapy versus conformal photon radiation therapy for childhood craniopharyngioma: multi-institutional analysis of outcomes, cyst dynamics, and toxicity. Int J Radiat Oncol Biol Phys 90(2): 354-361, 2014. PMID: 25052561, DOI: 10.1016/j.ijrobp. 2014.05.051

19 Pulsifer MB, Sethi RV, Kuhlthau KA, MacDonald SM, Tarbell NJ and Yock TI: Early cognitive outcomes following proton radiation in pediatric patients with brain and central nervous system tumors. Int J Radiat Oncol Biol Phys 93(2): 400-407, 2015. PMID: 26254679

20 Fournier-Goodnight AS, Ashford JM, Merchant TE, Boop FA, Indelicato DJ, Wang $\mathrm{L}$, Zhang $\mathrm{H}$ and Conklin $\mathrm{HM}$ : Neurocognitive functioning in pediatric craniopharyngioma: performance before treatment with proton therapy. J Neurooncol 134(1): 97-105, 2017. PMID: 28540667, DOI: 10.1007/s11060017-2492-y

Received December 18, 2018

Revised January 21, 2019

Accepted January 22, 2019 